\title{
Um Ambiente EAD para Promover Experiências de Aprendizagem Mediadas em uma Disciplina Presencial
}

André Luís Alice Raabe Júlia Marques Carvalho da Silva Lúcia Maria Martins Giraffa

\section{An Environment to Foster Mediated Learning Experiences in Classroom Courses}


Resumo. Este artigo apresenta a utilizaçăo de um ambiente de educação a distância (EaD) para auxiliar no atendimento adequado aos problemas de aprendizagem de uma disciplina presencial de algoritmos, disciplina fundamental nos cursos da área tecnológica. $O$ ambiente foi concebido a partir de uma perspectiva sóciointeracionista fundamentada na teoria das Experiếncias de Aprendizagem Mediadas (Feuerstein, 1998). O ambiente EaD proporciona a flexibilizaçāo dos locais e horários de estudo, bem como fornece as informaçōes necessárias para direcionar a atuaçāo dos professores/ mediadores. Os resultados preliminares fornecem indicios de uma melhora no atendimento aos alunos e da ampliaçāo das experiências de aprendizagem mediadas.

Palavras-chave: Experiências de aprendizagem mediadas; educação a distância; aprendizagem de algoritmos.

Abstract. This paper presents a distance-learning environment to help adequate assistance for students learning problems in a programming discipline of undergraduate technological courses. The environment was conceived in a socio-interactionist approach inspired in Mediated Learning Experience theory (Feuerstein, 1998). The distance-learning environment allows flexibility of place and time to study, and gives the information needed to guide mediators acting. The preliminary results indicate an enhancement in student assistance and the mediated learning experiences improvement.

Keywords: Mediated learning experiences, distance learning, programming learning.

BE, André Luis A.; SILVA, Jứlia Marques C. da: GIRAFFA Lucia Maria Martins. Um Ambiente de EAD para Promover Experiências de Aprendizagem Mediadas em uma Disciplina Presencial. Informática na Educação: teoria \& pratica, Porto Alegre, v.8, n.1, p. 89-101, jan.jun. 2005. 
Introdução

A disciplina de Algoritmos e Programaçāo caracteriza-se por ser de fundamental importância para 0 acadêmico que visa desenvolver seu raciocínio lógico e a prática com a programação em cursos da área tecnológica. No entanto, problemas de aprendizagem dos alunos tornam a disciplina um desafio na maioria dos cursos de graduação do Brasil (Esmin, 1998; Mendes, 2001; Menezes \& Nobre, 2001).

A disciplina caracteriza-se ainda por exigir do docente e seus auxiliares uma forte demanda de interação a fim de atender, acompanhar, mediar e avaliar individualmente os alunos. No entanto, na maioria dos casos, esta demanda de interação é inviável de ser atendida por motivos didático-organizacionais como, por exemplo, a grande quantidade de alunos em uma turma.

Os problemas de aprendizagem que ocorrem nesta disciplina são em sua maioria oriundos da ausência ou ineficácia das estratégias de solução de problemas utilizadas pelos alunos. Segundo Nurrenberg (1997, citado em Falkembach, 2003), os professores normalmente não são preparados para ensinar os alunos a resolverem problemas, e como conseqüência estes não estāo aptos para analisar enunciados, traçar conjecturas, identificar variáveis de entrada e saída e assim por diante.

Para reverter este quadro, encontrou-se na teoria das experiências de aprendizagem mediadas (Feuerstein, 1998) uma abordagem teórico-instrumental adequada para a compreensão dos processos cognitivos do aluno e a promoçāo de intervençōes para mediar o desenvolvimento de estratégias de soluçăo de problemas. Desta forma, buscou-se promover experiências de aprendizagem mediadas para atender adequadamente as demandas de interação dos alunos.

Para organizar e registrar as interações entre professores e alunos na disciplina presencial de Algoritmos, foi desenvolvido e utilizado um ambiente de Educaçâo a Distância (EaD) via Internet. Desta forma, aproveitou-se de aspectos da pedagogia online a fim de proporcionar novas alternativas de comunicação, flexibilização de local e ritmo de aprendizagem, divisão das responsabilidades com tutores/monitores e principalmente a possibilidade de um registro e acompanhamento mais detalhado sobre o desempenho individual de cada aluno, um aspecto fundamental para a 0 desenvolvimento de experiências de aprendizagem mediadas.

Este artigo está organizado da seguinte forma: a seção 2 apresenta resumidamente a obra de Reuven Feuerstein e a teoria das experiências de aprendizagem mediadas; a seçāo 3 caracteriza os problemas de aprendizagem de algoritmos; a seção 4 caracteriza a ocorrència de experiências de aprendizagem mediadas na disciplina de algoritmos; a seção 5 apresenta 0 ambiente virtual de aprendizagem que foi construído para apoiar o desenvolvimento de experiências de aprendizagem mediadas; a seção 6 discute os resultados preliminares e a seção 7 apresenta as conclusöes e perspectivas futuras deste trabalho.

\section{A Obra de Reuven Feuerstein}

A teoria das Experiências de Aprendizagem Mediadas (EAM) foi proposta por Feuerstein (1998), porém para compreendê-la adequadamente faz-se necessário conhecer um pouco da obra de Feuerstein como um todo.

Reuven Feuerstein é um pesquisador israelita que vem alcançando renome mundial 
pelo seu método desenvolvido com crianças deficientes. Feuerstein nasceu na Romênia em 1921. Estudou psicologia e pedagogia em Bucareste e depois prestou exames de licenciatura em Jerusalém. Estudou também em Genebra (onde trabalhou com André Rey e Jean Piaget), e na Universidade de Sorbonne em Paris.

Feuerstein definiu não só um conjunto de pressupostos teóricos, como também instrumentos práticos para sua aplicação. Os aspectos teóricos sāo influenciados principalmente pelos pressupostos sociointeracionistas de Vygotsky, mas também por aspectos construtivistas de Jean Piaget. Beyer (1996), afirma que o trabalho de Feuerstein possui interfaces claras com os pressupostos de Piaget e principalmente de Vygotsky. Gomes (2002), utiliza o termo "construção mediada do conhecimento" para caracterizar a obra de Feuerstein. Já os aspectos instrumentais foram desenvolvidos por meio de extensivos experimentos como populações culturalmente privadas (ver "síndrome da privação cultural" em Feuerstein, 1997).

Os principais pressupostos teóricos de seu trabalho são a teoria da Modificabilidade Cognitiva Estrutural (MCE) e a Teoria das EXperiências de Aprendizagem Mediadas (EAM). Os instrumentos práticos são a Avaliação Dinâmica do Potencial de Aprendizagem (ADPA); o Mapa Cognitivo e o Programa de Enriquecimento Instrumental que não serão apresentadas neste artigo por não terem sido utilizadas nesta pesquisa.

\subsection{Modificabilidade Cognitiva Estrutural}

Segundo a Teoria da Modificabilidade Cognitiva Estrutural (MCE), os seres huma- nos são vistos como indivíduos que têm a propensāo para modificar-se ou para serem modificados nas estruturas de seu funcionamento cognitivo, à medida que eles respondem às demandas de mudança de situaçōes de vida. A MCE ocorre quando as mudanças são caracterizadas por um determinado grau de permanência, profundidade e quando são generalizadas.

Os seres humanos são vistos como sistemas abertos, acessiveis a mudanças durante seu tempo de vida, correspondendo às condiçōes de mediaçāo, desde que a intervenção seja apropriadamente direcionada (em quantidade e qualidade) à necessidade do indivíduo. A inteligência é tida como a propensão ou tendência do organismo a ser modificado em sua própria estrutura, como resposta à necessidade de adaptar-se a novos estímulos, sejam de origem interna ou externa. Ela envolve a capacidade do individuo de ser modificado em sua estrutura cognitiva através da aprendizagem e a habilidade de aplicar autonomamente esta mudança em momentos futuros. (ICELP, 2004)

Dois paradigmas fundamentam a MCE: (1) A modificabilidade é uma condição filogenética da espécie humana, pertinente a todos os seres humanos (exceto em raríssimas situações); (2) A modificabilidade é proporcionada pelo fator sóciocultural.

\subsection{Experiência de Aprendizagem Mediadas}

Feuerstein (1997) define a mediação como sendo uma atitude intencional realizada por um sujeito mais experiente que tem a incumbência de preparar situaçốes que favoreçam o desenvolvimento cognitivo de seu apren- 
diz.

A Experiência de Aprendizagem Mediada é o processo pelo qual a modificabilidade cognitiva é atingida. A EAM requer a presença de três parâmetros que são 0 objeto de atençāo deliberada por parte do mediador. (i) Intencionalidade e Reciprocidade; (ii) Transcendência; e (iii) Significado. Esses parâmetros oferecem oportunidade ao mediador de fazer escolhas planejadas e sistemáticas para explorar o potencial de mediação em situaçōes para encorajar o funcionamento cognitivo e estimular a modificabilidade.

O processo de mediação vaí além de uma simples e orientada tarefa de um produto, de uma orientação de aprendizagem, objetiva tornar o indivíduo capaz de agir independentemente de situaçöes especificas, e isso torna o aprendiz capaz de se adaptar às novas dimensões com as quais ele irấ se defrontar.

A EAM afeta, de maneira significativa, a capacidade do indivíduo de ser modificado estruturalmente atravès da exposição direta a estímulos. Quanto mais o indivíduo vivencia EAM, maiores serão os benefícios adquirídos por aquela pessoa em funçāo da exposiçāo direta ao aprendizado; quanto menos EAM for recebida, menos uma pessoa estará apta a aprender a partir da exposiçăo direta.

Os termos "mediação" e "mediador" tern sido amplamente utilizados em contextos também amplos $e$, por essa razāo, é fundamental determinar os eiementos ou as características que, segundo Feuerstein (1997), constituem condição para que uma interação seja qualificada como mediaçāo. Os critérios fundamentais para que haja EAM são os seguintes:

\subsubsection{Mediaçăo de Intencionalidade e Reciprocidade}

Um dos primeiros elementos necessários é que o mediador tenha uma intenção com relação ao mediado e não apenas ofereça ao indivíduo a oportunidade de ver ou interagir com algum objeto. Assim que o mediado reconhece a intenção do mediador e a importância de sua atuação selecionando $e$ formatando a experiência, a reciprocidade é atingida. A reciprocidade proporciona ao aprendiz não somente um estímulo particular, mas também cria a necessidade dele descobrir, no mediador, qualidades subjetivas da interação (em direção a mediaçāo de significado).

Intencionalidade e reciprocidade são as características mais importantes da EAM, pois fornecem à interação uma qualidade muito superior a exposiçāo direta. Na exposiçāo direta há pouca possibilidade de prever quando um estímulo particular será percebido. Nas interações mediadas o mediador garante que o aprendiz irá perceber o estímulo que será importante para o desenvolvimento posterior da resposta. (Feuerstein, 1997)

\subsubsection{Mediação de Transcendência}

A mediaçāo de transcendência ocorre quando mediador e mediado caminham para além de um objetivo particular. Transcender é uma ação de transferência a qual se demonstra na capacidade que os indivíduos possuem de compreender determinadas situações ou objetos e extrapolar esse aprendizado para outras situaçōes nas quais o processo de apreendido pode ser aplicado novamente. O mediador busca tornar uma experiência particular em uma fonte de mudanças em diversas áreas, atingindo propósitos mais amplos e 
interaçōes mais abrangentes.

Transcendência é a forma pela qual os seres humanos são mediados para ampliar o seu sistema de necessidades, indo além de estados imediatos de necessidade (como a fome, por exemplo) para responder a novas necessidades transmitidas através da cultura (o desejo de comer um tipo particular de alimento) e a apropriação de novos repertórios. (Gomes, 2003)

\subsubsection{Mediação de Signíficado}

A mediação de significado é onde reside toda a transmissāo mediada de valores, atitudes culturais e pessoais do mediador para com o mediado. Ensinar é provocar nos individuos a busca por significados, sejam eles no ầmbito índividual ou coletivo. A educação para o significado inicia-se no eixo familiar, tanto no nível cognitivo (valores crenças, conhecimentos) quanto no nível afetivo (energia, entusiasmo, sentimentos), e amplia-se para outros contextos. $O$ individuo que fol educado dentro de um sistema onde the fol incentivado a busca da compreensāo dos significados dos fatos e eventos, passará a necessitar e a buscar significado no mundo circundante.

Feuerstein (1997 citado em Sarmento, 2002), crê que os novos conhecimentos somente serão apreendidos significativamente se alguns conceitos; considerados como relevantes, estiverem disponiveis na estrutura cognitiva do indivíduo, servindo de suporte para novas informaçốes.

Feuerstein (1997) ainda acrescenta que o objetivo deve ser de atingir o sistema de necessidades do aprendiz, pois com isso os elementos afetivo-motivacionais e emocionais criam as razões para fazer algo, o propósito de um comportamento. Os elementos cognitivos que mediam a intencionalidade/reciprocidade e transcendência são responsáveis pela estrutura do comportamento, enquanto que a mediação de significado representa o componente afetivo refletido na resposta das perguntas "Porque estou fazendo isso? Porque é importante que seja feito?"

A mediação de intencionalidade, de significado e de transcendência sāo as três caracteristicas fundamentais e universais para que uma interação adquira o status de EAM.

\section{Dificuldades de Aprendiza- gem de Algoritmos}

A aprendizagem de algoritmos é considerada fundamental para o acadêmico dos cursos da área computacional como ciência da computação, sistemas de informação, engenharia da computação e licenciatura em computação. Seu objetivo é de iniciar o desenvolvimento do raciocinio lógico e da prática com a programaçâo que será necessária no decorrer de todo o curso.

Esmin (1998) cita que a lógica para programaçẩo consiste em aprender a pensar na mesma seqüência em que o computador executa as tarefas, aprende-se a imaginar como as ações serão executadas partindo-se do estudo de um problema até chegar a construção de um algoritmo (solução).

Mendes (2001) afirma que as dificuldades encontradas são diversas, entretanto algumas aparecem com maior freqüência como o alto nivel de abstraçāo do conteúdo, que gera a necessidade de apresentar um bom nível de conhecimento e prática de técnicas de resoluçấo de problemas. Além disto; a diversidade de background dos alunos gera ritmos de apren- 
dizagem diferenciados o que dificulta um acompanhamento individualizado ao aluno.

A análise sistemática das relaçōes de ensino aprendizagem realizadas durante 6 semestres na disciplina de algoritmos e estruturas de dados do curso de Ciência da Computaçāo da Universidade do Vale do Itajaí apontam outros aspectos que contribuem para esta realidade, dentre eles destacam-se dois grupos distintos: problemas de natureza didática e problemas de natureza cognitiva.

\subsection{Problemas de Natureza Didática}

- Grande número de alunos: Em média 40 a 50 alunos o que impossibilita uma avaliação individualizada, um feedback mais efetivo e limita a quantidade de avaliaçöes que se pode realizar.

- Dificuldade de o professor compreender a lógica do aluno: Uma vez desenvolvido o raciocínio lógico, torna-se difićil pensar as soluções de outra forma. Como conseqüência, o professor tem grande dificuldade em compreender a lógica individual de cada aluno que os leva a construçōes equivocadas de algoritmos.

- Diferenca de experiência e ritmo de aprendizagem entre os alunos: Multos alunos que ingressam na disciplina já possuem alguma experiếncia em programação e ou trabalham na área tecnológica, enquanto que outros não possuem nenhum background.

- Ambiente de realização das provas: A realização das provas é normalmente o momento onde o aluno percebe a diferença entre observar e fazer. Isto é determinante na disciplina onde muitos alunos têm a sensação de estar entendendo, mas não percebem sua incapacidade de fazer. Aliado a isso, a realizaçăo de prova é um momento de tempo limitado, pressão e stress que certamente não favorecem o raciocínio.

- Pouco uso dos monitores da disciplina: Os alunos com dificuldades de aprendizagem procuram muito pouco a ajuda dos monitores da disciplina, mesmo com a divulgação sistemática dos horáríos e locais de atendimento. Aparentemente os alunos depositam pouca credibilidade às orientaçōes provenientes dos monitores.

- Ausência de bons materiais: Existem muitos livros de algoritmos, mas geralmente estes apresentam o conteúdo de uma forma que o aluno tem dificuldade de compreender. Os livros acabam sendo usados mais pelos professores para organização do curriculo e seleção de exercicios. É provável que o mesmo problema que faz o docente nāo compreender a lógica equivocada de certos alunos se manifeste nos autores de livros que não conseguem ter a visão de aluno aprendiz. Além disso, praticamente inexistem livros que sejam direcionados para o ensino autônomo.

- Alunos desorientados na escolha do curso: Por ser uma disciplina de primeiro semestre, muitos alunos não tem uma visão correta sobre o perfil do curso e acabam descobrindo isso durante a disciplina. Em muitos casos, uma visão equivocada sobre o curso cria um ambiente de incompreensão e de descaso frente aos desafios da disciplina. 


\subsection{Problemas de Natureza Cognitiva}

- Alunos sem perfil para solução de problemas: Muitos alunos não desenvolveram adequadamente estratégias para soluçẵo de problemas durante o ensino médio, e por isso apresentam maior dificuldade com a disciplina.

- Alunos sem base operatório-formal: 0 raciocínio operatório formal, base para compreensão do raciocínio lógico, não foi adequadamente desenvolvido no ensino médio.

- Conteúdo sem proximidade com o conteúdo escolar: A lógica algorítmica ê algo totalmente novo para a maioria dos alunos, e com isso eles não conseguem estabelecer relações com conteúdos já apreendidos anteriormente, principalmente a matemática.

\section{Experiências de Aprendizagem Mediadas em Algoritmos}

Um aspecto que motivou a busca pelo apoío teórico nas EAM é a sua proximidade com o processo de ensino e aprendizagem a partir da resolução de problemas. A disciplina de algoritmos tradicionalmente dispóe ao aluno uma grande quantidade de problemas a serem resolvidos, e o desempenho deste na solução dos problemas fornece indicadores para a atuação do docente.

Pode-se entender muitos dos processos de interação entre professor e aluno nesta disciplina como experiências de mediação que, se devidamente conduzidas, podem levar a aprendizagem.
A mediaçāo de intencionalidade pode ocorrer se o docente/mediador intervir junto ao aluno de forma a organizar uma situação de aprendizagem específica, adaptada a necessidade particular deste aluno (adequação ao potencial de aprendizagem individual de um determinado aluno). Muitas vezes isto ocorre quando $o$ professor percebe que o aluno năo compreendeu adequadamente um conceito, como por exemplo instruções para entrada de dados, e com isso ele direciona a este aluno uma determinada situação problema na qual a identificaçăo do significado deste conceito fazse necessária e torna-se facilitada. Se o aluno perceber positivamente (no sentido de aceitaçâo e engajamento) a intenção do mediacior então terá sido criada a reciprocidade, ou em outras palavras, 0 aluno acredita que a forma que $o$ mediador está organizando as atividades podem levá-lo a aprender. Note-se que existe um forte componente afetivo envolvido nesta forma de interação.

Já a mediaçăo de transcendência para ocorrer depende de que o mediador incentive 0 aluno a generalizar o conhecimento adquirido para situações mais amplas, ou seja transformar o domínio de um determinado conteúdo em uma ferramenta para a soluçăo de problemas mais amplos. Neste aspecto é onde muitos mediadores têm falhado junto aos alunos. Por exemplo, a explicação do funcionamento de um laço de repetição não leva a compreensão de que problemas de natureza iterativa (repetitiva) podem ser solucionados com laços de repetição. É imprescindivel que o mediador apresente situaçóes problema relacionadas ao cotidiano dos alunos onde a solução necessita de um laço de repetição. Desta forma o aluno pode transcender a soluçāo de um problema especifico para uma classe mais geral de problemas. 
Já a mediação de significado é a mais comum e normalmente ocorre em conjunto com as outras duas formas de mediação. Ela compreende a transmissão da informaçāo necessária para a compreensāo das técnicas de construção de algoritmos e principalmente o reconhecimento dos problemas que podem ser solucionados a partir destas técnicas. No entanto 0 objetivo da mediação de significado deve ser o de atingir o sistema de necessidades do aprendiz, mobilizando os elementos afetivo-motivacionais que criam as razões para 0 engajamento.

Para o professor fica a grande tarefa de atender as demandas de aprendizagem dos alunos, identificar 0 potencial de modificabilidade cognitiva de cada um e proporcionar experiências de aprendizagem mediadas. Nota-se que para isso faz-se necessário um maior tempo de dedicaçà̃o do docente, um maior tempo de interação e convivência com os alunos, uma maior participação dos monitores da disciplina e uma organizaçāo das atividades de aprendizagem que respeitem a diferença de ritmo e experiência entre os alunos.

Desta maneira, decidiu-se desenvolver e utilizar um ambiente EaD como forma de ampliar os momentos de interação entre professor, aluno e monitores, auxiliando na identificação e acompanhamento das dificuldades de aprendizagem dos alunos da disciplina.

\section{O Ambiente Alice de Educação a Distância}

O ambiente Alice foi concebido para ser utilizado como uma ferramenta complementar ao ensino presencial, possibilitando aos alunos flexibilizar os limites de tempo e espaço da sala de aula, exercitar seus conhecimentos com maior freqüência e interagir com colegas, monitores e professores na busca de soluçōes dos problemas de aprendizagem. Alice é o nome da personagem presente na interface do sistema.

A seguir descrevem-se as tarefas desenvolvidas por alunos e professores e monitores no ambiente.

\subsection{Alunos}

Na visão do aluno o ambiente está organizado em treze seções divididas da seguinte maneira:

- Materiais de referencia (Dicas, Tutoriais, Apostilas, Links, Códigos-fonte, Parede da Fama ):

- Ferramentas de apoio (Downloads);

- Entretenimento (Recreio)

- Ferramentas de Socialização (Alunos e Meus Dados)

- Ferramentas de Interação (Praticando e Correio);

Nos materiais de referência os alunos encontram informações de apoio a aprendizagem (ilustrados na figura 1), as ferramentas de apoio sāo softwares que ajudam o aluno a desenvolver algoritmos, 0 entretenimento são jogos de lógica em flash que servem como uma brincadeira de aprendizagem, as ferramentas de socialização referem-se aos dados pessoais e dos colegas e as ferramentas de interaçāo permitem ao aluno interagir com professores, monitores e colegas, em especial resolvendo exercicios. 


\section{reura netion}

Os exercícios são compostos por questōes objetivas (corrigidas automaticamente) e algoritmos (corrigidas pelos professores $\theta$ monitores). A figura 2 ilustra a tela de realização de um exercício por um aluno.

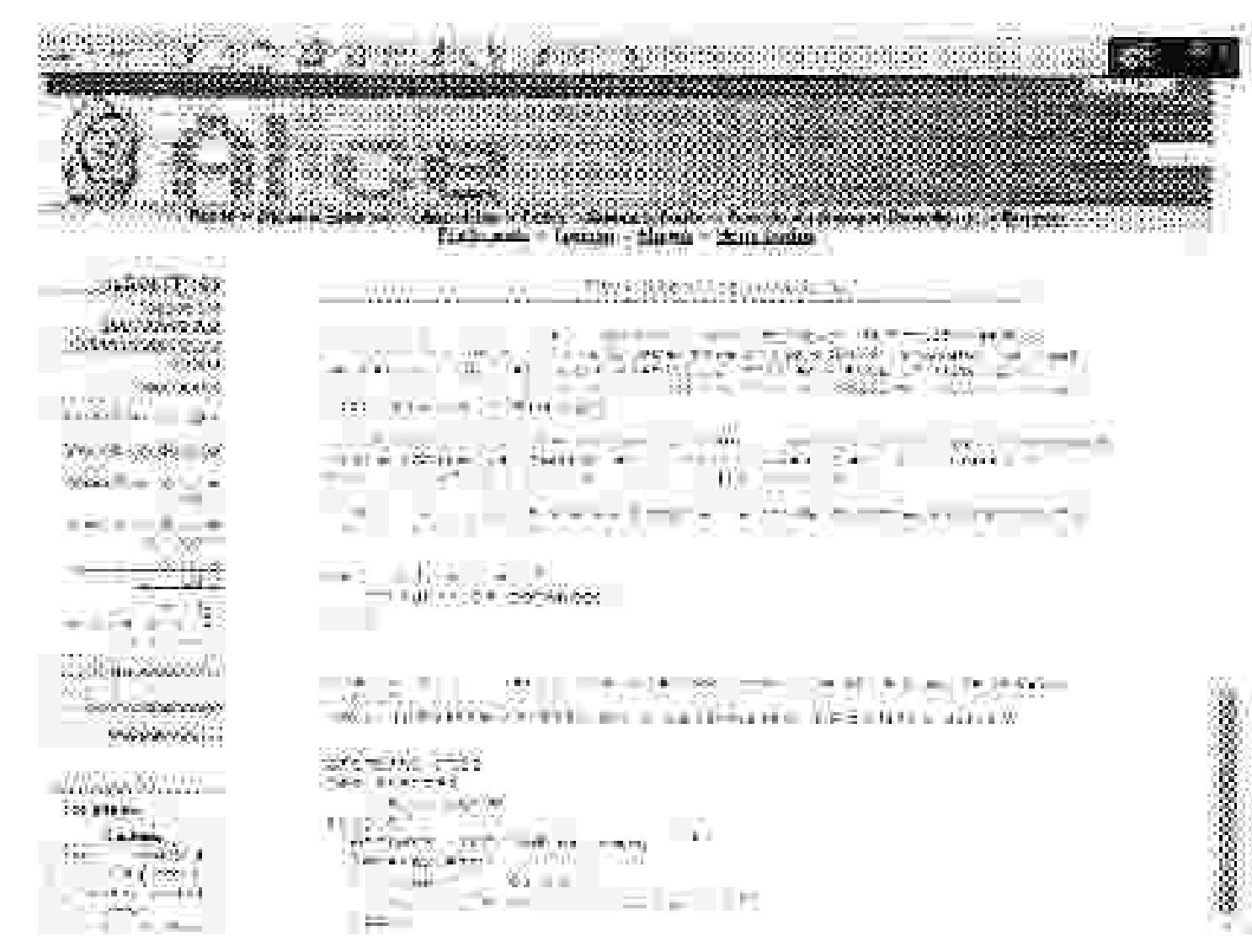

Figura 1 - Textos exibidos ao aluno.

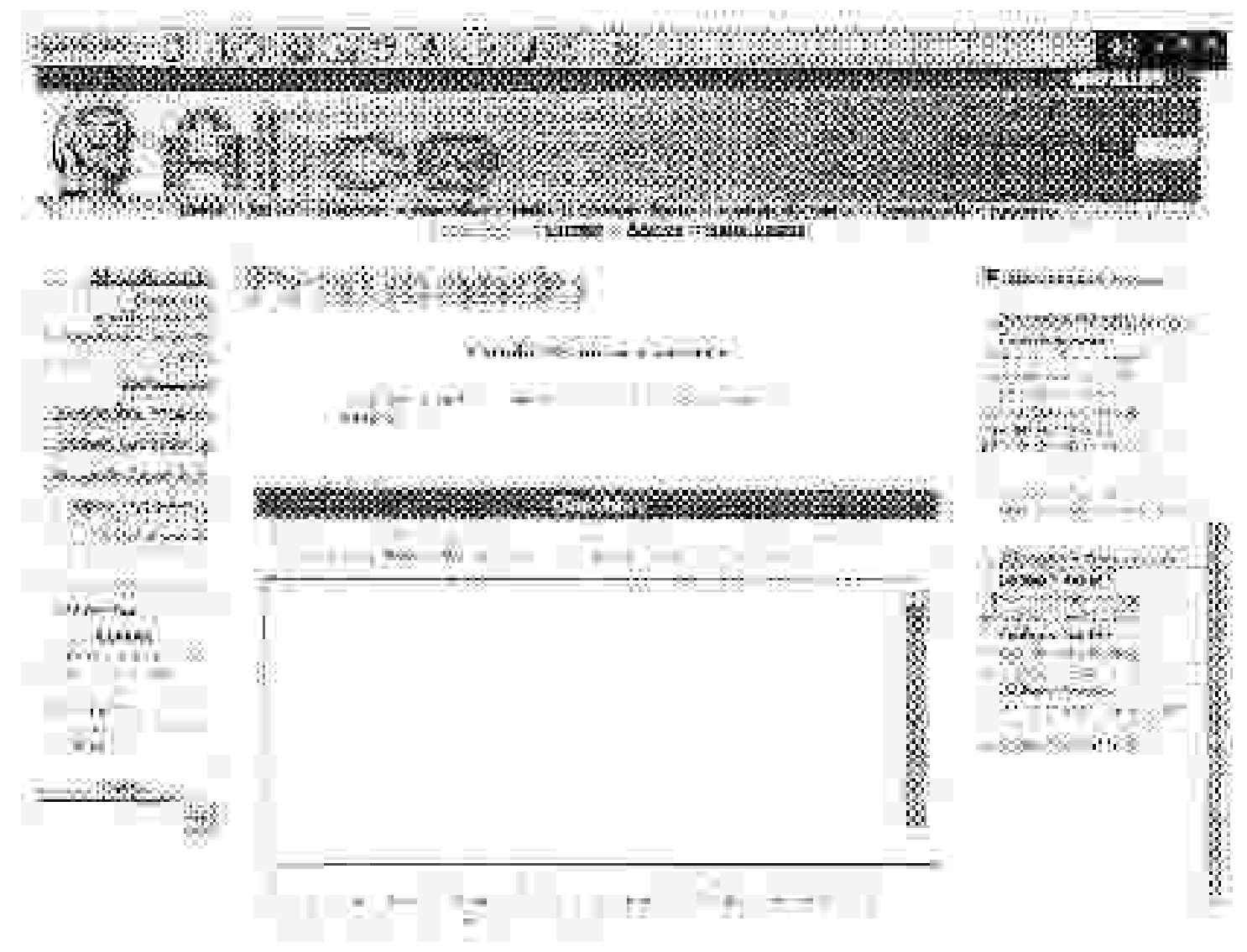

Figura 2 - Exercicios sendo realizados

\subsection{Mediadores}

Os mediadores estāo divididos em professores e monitores, ambos interagem com os alunos da mesma forma no ambiente. A diferença é que o professor ministra as aulas presenciais.

0 ambiente Alice, como muitos ambientes $\mathrm{EaD}$, coloca a disposição dos mediadores todo o gerenciamento organizacional das informaçōes disponibilizadas ao aluno tais como a distribuição dos conteúdos em unidades $\theta$ conceitos, os materials de referencia, ferramentas para downioad, e assim por dian- te. No entanto o diferencial deste ambiente encontra-se no acompanhamento dos problemas de aprendizagem dos alunos.

Os mediadores são sempre avisados quando algum aluno realizou um exercício que deve ser corrigido. Neste momento é que uma Experiência de Aprendizagem Mediada começa a tomar forma.

Ao corrigir um exercício o mediador tem à sua disposiçāo um conjunto de informaçôes sobre o aluno e seu histórico na disciplina, de forma que ele já possui um conhecimento preliminar das dificuldades de aprendizagem deste aluno. Quando avalia o algoritmo desenvolvido pelo aluno e indica o que pode estar errado, está mediando significado, pois inevitavelmente a indicaçăo de um erro deve vir acompanhada deste tipo de mediação (a simples atribuição de notas nāo contribui em nada para. a aprendizagem neste caso). Cada exercício está associado a um conjunto de conceitos pré-requisitos que auxillam ao mediador na identificaçāo da causa do problema que levou o aluno ao erro.

A maior contribuiçāo desta abordagem para a constituição de EAM ocorre a partir da análise dos registros das interaçōes e no replanejamento das açōes nos encontros presenciais, A figura 3 ilustra uma visão geral dos problemas de aprendizagem de cada aluno.

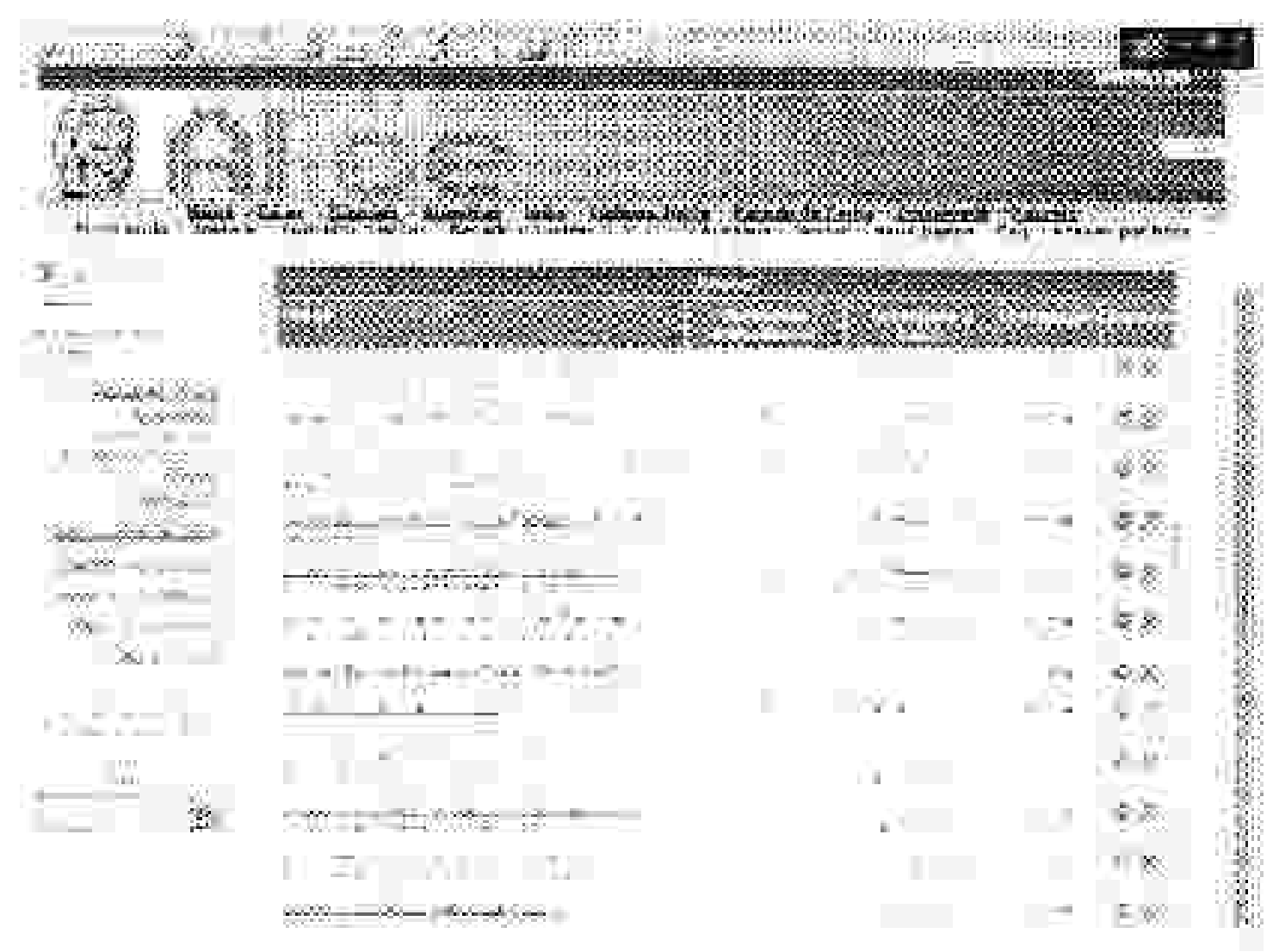

Figura 3 - Alunos e seus problemas de aprendizagem. 
O mediador pode ainda visualizar os detalhes do desempenho do aluno ao longo do curso analisando as estatísticas de acesso por quantidade de acesso; último acesso; quantidade de mensagens enviadas; caminho realizado no ambiente; aulas, textos e exercícios já acessados além do desempenho do aluno nestes exercícios e as respectivas dificuldades de aprendizagem diagnosticadas. A figura 4 ilustra como um determinado aluno distribuilu seu tempo de utilização do ambiente.

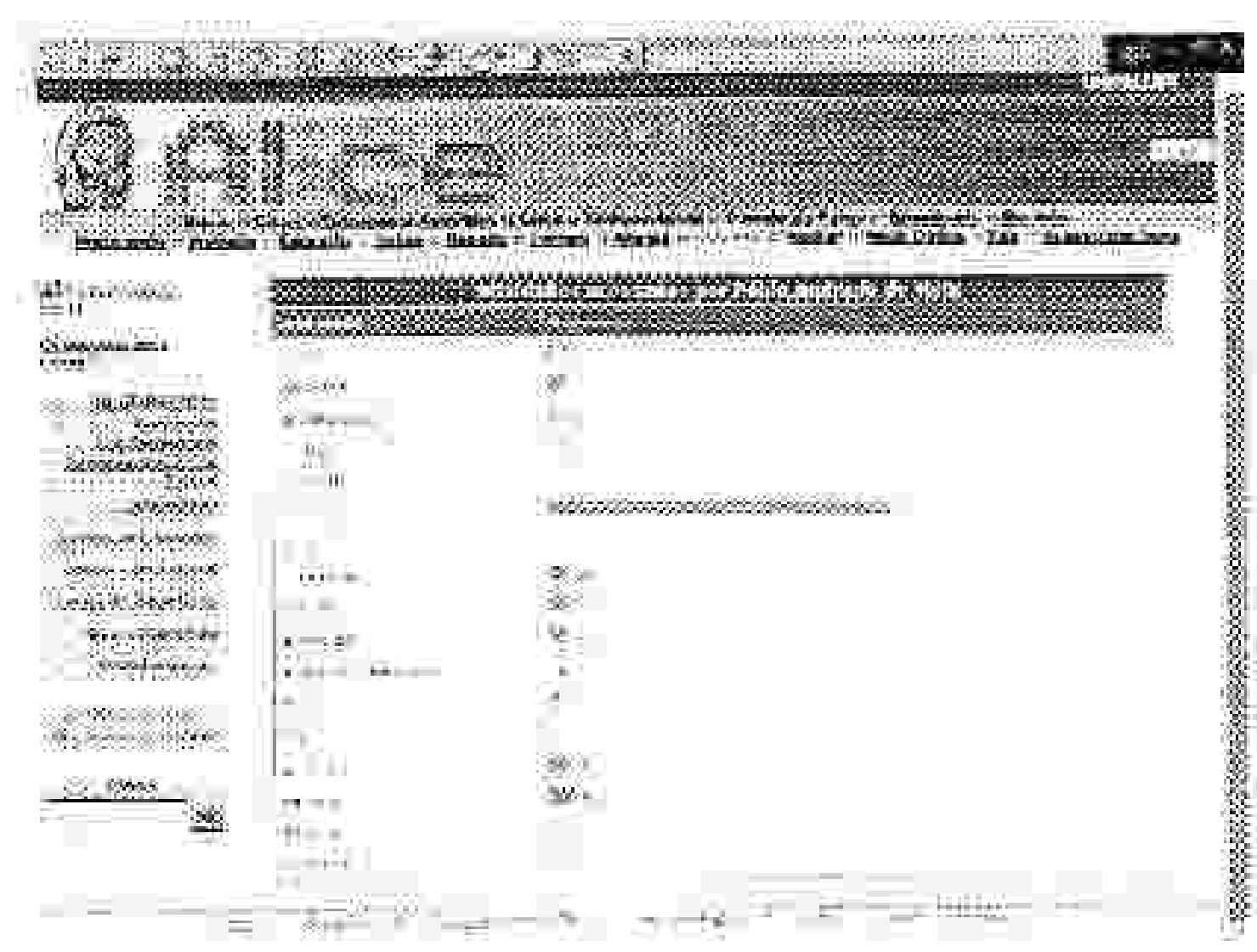

Figura 4-Analisando um deteminado aluno

\section{Resultados preliminares}

A utilização do ambiente Alice na disciplina de algoritmos nāo substituiu nenhum encontro presencial, sua utilização foi planejada para horários extra-classe. Apenas uma aula em laboratório foi utilizada para passar instruçōes básicas de acesso e utilização do ambiente. A utilização do ambiente deveria expandir os limites da aula presencial.

Desta forma, acredita-se que estão sendo aproveitadas características tanto do ensino presencial quando do virtual. Segundo Moran (2003), vale a pena utilizar ambientes virtuais como ampliaçăo do espaço e tempo da sala de aula tradicional, mas lembrando que tais ambientes não são uma panacéia para a aprendizagem nem substituem a necessidade de contatos presenciais periódicos.

O ambiente está sendo utilizado por duas turmas, totalizando 81 alunos, 1 monitor e 2 professores. A maior freqüência de acessos dos alunos tem ocorrido nas quintas-feiras e sábados e nos horários entre 15 e 19 hs e após a meia noite. Estes dados indicam que os horários e locais de estudo têm sido flexibilizados pelo uso do ambiente, pois a disciplina é lecionada nas quartas e sextas feiras no turno da noite. Os recursos mais acessados são as ferramentas de correio e o perfil dos alunos.

A atuaçāo dos profiessores e monitores tem sido freqüente no atendimento das dúvidas e resoluçăo dos exercícios, porém as mediaçōes de intencionalidade significado e transcendência têm se mostrado difíceis de serem efetivadas somente com as ferramentas de comunicação disponíveis no ambiente.

A principal contribuição do ambiente tem sido em manter um registro detalhado sobre as tarefas, exercicios e problemas de aprendizagem apresentados pelos alunos, a partir das anotações realizadas pelos mediadores na correção dos exercícios. A ampliação das possibilidades de interação proporcionadas pelo ambiente tem fornecido dados preciosos para o professor sobre o perfil dos alunos, as dificuldades de aprendizagem, características pessoais, comportamentos e etc, que sem a existência deste ambiente dificilmente seriam utilizadas a favor da aprendizagem do aluno.

Os dados fornecidos pela ferramenta têm sido fundamentais para re-orientar a atuação dos professores em direção a promover mediaçốes de intencionalidade e 
transcendència nos períodos de aula presencial.

Um outro aspecto em que a ferramenta tem contribuído é na divisāo de responsabilidades entre professores e monitores (mediadores). No ambiente virtual, não existe a distinção entre turmas, e todos interagem atendendo os alunos e auxiliando a alimentar o perfil individual de cada aluno.

\section{Conclusões}

Os resultados da utilização do ambiente fornecem indícios de que os problemas de aprendizagem da disciplina têm recebído uma atenção mais direcionada, estruturada e subsidiada por informações que antes nāo estavam sendo consideradas.

A teoria das experiências de aprendizagem mediadas tem fornecido um excelente aporte teórico para apoiar a atividade dos mediadores na avaliação e orientação dos processos de aprendizagem dos alunos. Neste aspecto, a principal contribuiçāo do ambiente Alice, até o momento, tem sido em fornecer maiores subsídios para a avaliaçāo e posterior mediaçăo dos alunos. Desta forma, as experiências de aprendizagem mediadas têm sido facilitadas nos encontros presenciais, a partir das informações disponiveis no ambiente virtual.

Porem a demanda de trabalho dos docentes e monitores aumentou significativamente, como jấ era esperado. Neste sentido, as perspectivas futuras deste trabalho incluem o desenvolvimento de um ITA (Intelligent Teaching Assistant) para que certas modalidades de diagnóstico de problemas de aprendizagem possam receber uma mediação de intencionalidade sem a intervençăo do mediador humano, ou seja, o ITA sugerir atividades de aprendizagem automaticamente aos alunos.

Acredita-se que a utilização de ambientes virtuais computadorizados pode contribuir significativamente para melhoria dos processos de ensino/aprendizagem de disciplinas presenciais. $O$ desenvolvimento de pesquisas que busquem encontrar um dimensionamento adequado entre atividades presenciais e virtuais pode fornecer indicadores importantes para o planejamento de ambientes computadorizados e de estratégias didáticas que tirem proveito do melhor de ambas as modalidades. 


\section{Referências}

BEYER, H. O.. O Fazer Psico-Pedagógico: A abordagem de Reuven Feuerstein a partir de Piaget e Vygotsky. Porto Alegre: Mediação Editora, 1996.

ESMIN, A. A. A. Portugol/Plus: Uma Ferramenta de Apoio ao Ensino de Lógica de Programaçăo Baseado no Portugol. In: IV Congresso RIBIE, Brasília, 1998.

FALKEMBACH, G. A M. Uma Experiência de resolução de problemas através da estratégia ascendente. Tese de Doutorado, PGIE - UFRGS, Porto Alegre, 2003.

FEUERSTEIN, R. Early Detection: Blessing or Curse. In: Approaches to Developmental and Learning Disorders - Theory and Practice, Proceedings p. 253-276, 1997.

. The Theory of Mediated Learning Experience: About The Human as a Modifiable Being. Ministry of Defense Publications, Jerusalem, 1998.

GOMES, C. M. A. Feuerstein e a Construçāo Mediada do Conhecimento. Porto Alegre: Artmed Editora, 2002.

ICELP - International Center for Enhancement of Learning Potential. Basic Theory. Disponivel em: http://www.icelp.org/asp/Basic_Theory.shtm. Acesso em: fev. 2004.

MENDES, A. J. N. Software educativo para apoio à aprendizagem de programação. In: Taller Internacional de Software Educativo, 2001, Santiago. Disponivel em: <http://www.c5.cl/ieinvestigal actas/tise01/pags/charlas/charla_mendes.htm>

MENEZES, C. S.; NOBRE, I. A. M. Um Ambiente Cooperativo para Apoio a Cursos de Introdução a Programação. In: XXII Congresso da Sociedade Brasileira de Computação, Florianópolis, 2002.

MORAN, J. M. Contribuiçōes para uma pedagogia da educaçāo online. In: Silva, Marco (Org.). Educaçăo Online. São Paulo: Editora Loyola, 2003. p. 39-50.

SARMENTO, D.F. A Teoria da Modificabilidade Cognitiva Estrutural: Pressupostos Teóricos e Metodológicos. Revista da AOERGS, Porto Alegre. Ano 6, N 4, p. 12-22, 2002.

Recebido em março de 2004

Aceito para publicaçāo em outubro de 2004

André Luís Alice Raabe

Docente e pesquisador da Universidade do Vale do ltajaí Coordenador do Grupo de Desenvolvimento de Software

Educacional

Doutorando em Informática na Educação PGIE-UFRGS

E-mail:araabe@cttmar.univali.br Júlia Marques Carvalho da Silva

Acadêmica do Curso de Ciência da Computaçáo

da Universidade do Vale do Itajaí

E-mail:julia@ctmar.univali.br

Lúcia Maria Martins Giraffa

Doutora em Ciência da Computaçăo-UFRGS;

Professora Colaboradora do Doutorando em

informática na Educação PPGIE-UFRGS

E-mail:giraffa@pucrs.br. 


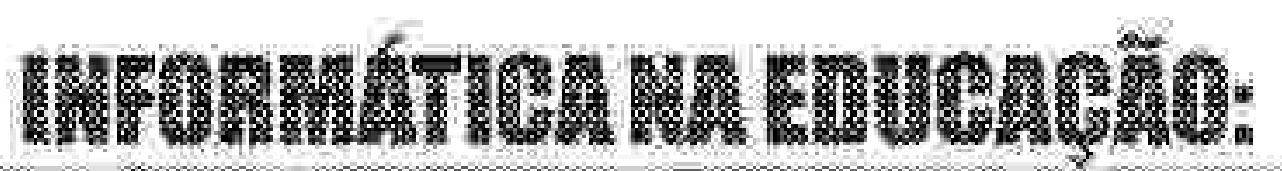

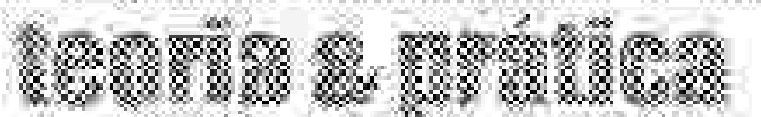

